\title{
Novas estratégias de posicionamento na fidelização do consumidor infantil de alimentos processados
}

\author{
New positioning strategies for fidelization of child consumers of processed food
}

\author{
Ângela Rozane Leal de Souza' Jean Philippe Palma Révillion ${ }^{\mathrm{II}}$
}

\section{- REVISÃO BIBLIOGRÁFICA -}

\section{RESUMO}

As crianças estão assumindo um papel cada vez mais importante nas decisões de consumo familiar em função de sua crescente influência e autonomia na escolha dos produtos adquiridos, o que as torna um segmento de mercado cada vez mais visado nas estratégias de marketing das empresas de produtos manufaturados. Essa dinâmica é particularmente importante no mercado de alimentos infantis, em que se estabelecem necessidades, às vezes contraditórias, de integrar a busca por alimentos saudáveis (pelos pais) saborosos e valorizados (muitas vezes em função de atributos extrínsecos) pelos filhos. Esta pesquisa evidenciou que a adoção de padrões de alimentação inadequados tem gerado a emergência de novos problemas de saúde na população infantil brasileira. Esse quadro é agravado por um contexto institucional marcado pelo conflito de parte do setor processador de alimentos $e$ órgãos públicos de regulação - em particular no que diz respeito à competência de regular a publicidade de alimentos para esse segmento de consumidores. Ao largo desse debate, as empresas líderes no mercado de alimentos infantis, em grande parte multinacionais, procuram alinhar a oferta de alimentos cada vez mais saudáveis aos consumidores infanto-juvenis, atendendo uma tendência inexorável nesse setor. É inconcebível, portanto, que o estabelecimento de uma regulamentação rígida e específica sobre as informações veiculadas na propaganda e publicidade de alimentos, voltados ao público infantil, por órgãos públicos isentos, beneficiando não apenas os consumidores, mas também a empresa preocupada em garantir a boa qualidade de seus produtos, não represente uma bandeira comum do setor processador de alimentos no Brasil.

Palavras-chave: alimentos, consumidor infantil, marketing.

\begin{abstract}
Children have taken an increasingly important role in consumption-related family decision-making due to a growing influence and autonomy in choosing the products to be bought, and this has turned them into a market segment that has is increasingly aimed at by marketing strategies of manufacturing companies. This dynamics is particularly important in the children food market, in which needs of integrating the search for foods that are both considered healthy (by the parents) and seen as tasteful and valued by the children (often because of extrinsic attributes) have been established, even though they can be sometimes regarded as contradictory. This research has evidenced that the adoption of inadequate nutrition patterns have caused the emergence of new health problems in the Brazilian children population. This picture has become more serious due to an institutional context marked by the conflict between the food processing industry and public regulation institutions - particularly concerning the competence to rule food advertising aimed at this consumer segment. Far from this debate, companies that are leaders in the children food market, most of which are multinational, attempt to align their offer of healthier foods to children and adolescent consumers, thus meeting an inexorable trend in this industry. Therefore, it is unconceivable that the establishment of a strict, specific regulation of the information provided in the advertisement and publicity of children food by impartial public institutions, not only benefitting consumers, but also the companies that are concerned about assuring the good quality of their products, does not represent a common purpose of the food processing industry in Brazil.
\end{abstract}

Key words: food, child consumer, marketing.

IPrograma de Pós-graduação em Agronegócios, Centro de Estudos e Pesquisas em Agronegócios (CEPAN), Universidade Federal do Rio Grande do Sul (UFRGS), Porto Alegre, RS, Brasil.

IIPrograma de Pós-graduação em Agronegócios, CEPAN, UFRGS, Av. Bento Gonçalves, 7712, Prédio da Agronomia, 1º andar, 91540-000, Porto Alegre, RS, Brasil. E-mail: jeanppr@gmail.com. Autor para correspondência. 


\section{INTRODUÇÃO}

A valorização do potencial da criança como consumidora é uma tendência global. A publicidade e o processo de comercialização voltados à infância não estão somente focados por empresas que fabricam e/ou comercializam brinquedos, filmes e vestuários, mas também, e muito fortemente, pelo segmento de produtos alimentícios.

Segundo pesquisa realizada pela INTERSCIENCE (2003), as crianças brasileiras influenciam cerca de $80 \%$ das decisões de compra de uma família. Dentre as categorias de produtos mais suscetíveis à influência dos filhos estão os produtos alimentícios industrializados. Desses produtos, estão no topo da influência a compra de biscoitos e bolachas (87\%), refrigerantes (75\%), salgadinhos (70\%), seguidos de achocolatados, balas/chocolates, iogurtes, macarrão instantâneo, cereais e sorvetes.

Esta pesquisa bibliográfica tem como principal objetivo descrever os principais fatores socioeconômicos e institucionais que condicionam essa dinâmica e avaliar, frente a esse contexto, a adequação das estratégias de posicionamento adotadas pelas indústrias alimentícias para a fidelização do consumidor infantil de alimentos.

Fatores socioeconômicos condicionantes, propaganda e padrão de consumo de alimentos infantis

Constata-se, atualmente, uma mudança significativa na vivência da infância e adolescência, principalmente devido ao acesso diário e prolongado ao computador e à televisão. Observa-se também que, no decorrer das programações televisivas e nas páginas da internet, ações publicitárias voltadas a esse segmento estão cada vez mais presentes (SAMPAIO, 2009).

No Brasil, segundo o Painel Nacional de Televisão do IBOPE, realizado em 2005, as crianças de quatro a onze anos assistiram à aproximadamente cinco horas de televisão por dia, ultrapassando inclusive os Estados Unidos na quantidade de tempo durante o qual as crianças ficam diante do televisor (VILLELA, 2010).

Isso traz à tona a preocupação com a propaganda de alimentos pouco saudáveis. HENRIQUES (2010) destaca que o excesso de comerciais voltados ao público infantil de alimentos pouco nutritivos ou fast foods, na mídia brasileira, gera o consumo exagerado de tais produtos nas crianças e tem ligação direta com o aumento do número de crianças obesas.

Tal fato é relevante, pois, de acordo com dados publicados pelo IBGE (2009), uma em cada três crianças na faixa dos 5 aos 9 anos, no Brasil, está acima do peso considerado adequado pela Organização
Mundial de Saúde (OMS). A Sociedade Brasileira de Pediatria (2008) adverte que o excesso de peso pode favorecer o desenvolvimento de doenças como as alterações osteomusculares, o colesterol alto, a hipertensão arterial, o diabetes mellitus e doenças cardiovalculares. De fato, esses tipos de doenças que, no passado, eram quase exclusivamente relacionadas ao público adulto já começam a ser verificados, com maior frequência, em crianças e adolescentes com excesso de peso.

Os índices de crianças com sobrepeso são uma tendência que acompanha o crescimento do volume investido no marketing infanto-juvenil pela indústria alimentícia. Pesquisa realizada pela Associação Brasileira de Agências de Publicidade, em 2003, aponta o Brasil como o terceiro país em investimentos em publicidade no mundo, sendo que $89,7 \%$ dos alimentos anunciados destinados a crianças são ricos em gordura, açúcar ou têm baixo teor nutricional (HENRIQUES, 2008).

Outro fato que merece destaque com relação à alimentação infantil é a crescente influência da participação da mulher no mercado de trabalho, que passou de 19\%, em 1940, para 42\%, em 2000 (INTERSCIENCE, 2003). A conciliação da vida profissional com a vida pessoal e familiar pode representar uma sobrecarga para a mulher, tornando o tempo dedicado à família cada vez mais escasso. Nesse panorama, no que se refere à nutrição, muitas vezes, as tradições e os hábitos alimentares saudáveis são modificados em favor de refeições rápidas ou de alternativas para suprir as necessidades familiares, como, por exemplo, a aquisição de refeições prontas ou o seu consumo em restaurantes (PESSOA, 2006).

Além desses fatos, a pesquisa da INTERSCIENCE (2003) aponta ainda outros fatores que motivam o consumismo infantil. Segundo esse estudo, os pais e as mães que trabalham fora se mostram menos resistentes aos pedidos das crianças, realizando uma espécie de compensação na compra de produtos que os filhos desejam em virtude do sentimento de culpa pela ausência diária, havendo assim uma maior permissividade. Destaca-se ainda que, dentre os itens habitualmente mais solicitados pelas crianças, estão os produtos alimentícios supérfluos. Nessa conjuntura, salienta-se também que, dentre as atividades compartilhadas entre pais e filhos, os passeios aos shoppings são cada vez mais corriqueiros, sendo um local de habituais paradas para compras de fast foods (hambúrgueres, cachorros-quentes, pizzas, batatas fritas, doces, etc).

Cabe salientar que os alimentos processados tendem a apresentar concentrações de gordura, açúcar e sal excessivas e prejudiciais à saúde. 
Essa condição foi comprovada por estudo do Instituto Brasileiro de Defesa do Consumidor - IDEC - sobre a composição nutricional de 30 alimentos industrializados, amplamente consumidos pela população brasileira, particularmente por crianças e adolescentes. $\mathrm{O}$ estudo demonstrou que bolinhos e salgadinhos apresentavam conteúdo de açúcar, gorduras e sal que excede em várias vezes o máximo recomendado para uma alimentação equilibrada e saudável. De acordo com o estudo, uma única porção de alguns desses alimentos continha quase todo o sal, açúcar ou gordura saturada que uma criança poderia consumir ao longo de todo o dia. A pesquisa evidenciou que a composição nutricional informada pela indústria nas embalagens dos produtos nem sempre foi fiel ao conteúdo. Além disso, sua publicidade envolvia procedimentos condenáveis e já não praticados pelas mesmas indústrias multinacionais em outros países, tais como o emprego de personagens famosos do universo infantil e a presença de brindes nas embalagens (IDEC, 2009).

SCHOR (2009), a partir de duas pesquisas, uma investigação qualitativa sobre anúncios e comerciais para crianças e uma avaliação do impacto da cultura do consumo nas crianças, com reflexos em sentimentos como depressão, autoestima, ansiedade e qualidade da relação com os pais, apresenta estudo que traz uma análise de como a propaganda e o marketing infantil influenciam as crianças, utilizando-se de estratégias nem sempre transparentes. A autora destaca um estudo de COTUGNA \& GAMBLE (1999), os quais evidenciaram que, entre 353 anúncios que iam ao ar nas manhãs de sábado, nas redes de televisão infantis, $63 \%$ eram de alimentos processados (petiscos, salgadinhos, fast food e outras guloseimas como refrigerantes, etc.) e salientam: "ninguém era convidado a comer brócolis”. Foram examinados 25 anos de anúncios na manhã de sábado e, com exceção de alguns anúncios de serviços público, "não havia nenhum anúncio de frutas ou de vegetais” (SCHOR, 2009, p.124).

Um estudo de CAIRNS et al. (2009), após análise de 115 estudos sobre a extensão e natureza da promoção de alimentos às crianças, concluiu também, quanto à propaganda de produtos alimentícios, que a maioria dos alimentos divulgados possui altos teores de gorduras e calorias, altas quantidades de açúcar e/ ou sal, contrariando normas internacionais das orientações dietéticas. Os cereais açucarados, refrigerantes e salgadinhos são as categorias mais frequentemente veiculadas, e a promoção de fast foods continua a ganhar quota de marketing. De acordo com a pesquisa, a promoção de alimentos não processados, como frutas e legumes, é quase zero.
O ambiente institucional e seu impacto na propaganda de alimentos infantis

Segundo o relatório do Fórum sobre a Comercialização de Alimentos e Bebidas Não Alcoólicas para Crianças, realizado pela Organização Mundial da Saúde - OMS - em maio de 2006, o governo tem o papel de restringir propagandas que depreciem a autoridade dos pais e de proteger as crianças contra as práticas comerciais que prejudiquem a sua saúde. Conforme esse estudo, para atingirem esse objetivo, as autoridades governamentais devem: (a) definir padrões nutricionais desejáveis para os diferentes tipos de alimentos que podem ser comercializados para crianças de diferentes idades; (b) aplicar restrições à comercialização e promoção de todos os alimentos que ficam abaixo desses padrões nutricionais (WHO, 2006). Desde esse evento, a OMS passou a elaborar um conjunto de recomendações sobre a comercialização de alimentos e bebidas não alcoólicas para crianças, a fim de reduzir o impacto dos alimentos ricos em gorduras saturadas, transgraxos ácidos, açúcares livres ou sal. Essas recomendações foram aprovadas durante a Assembléia Mundial da Saúde, em maio de 2010 (WHO, 2010). Porém a OMS transpôs a responsabilidade de tomar as medidas necessárias para implantação, monitoramento e avaliação das recomendações aos Estados-membros.

Existem esforços, em países como a Noruega, Suíça, Alemanha e Itália, para regulamentar a publicidade dos produtos alimentícios. Por exemplo, pelas regras de conduta do Conselho Alemão de Publicidade, é proibida a publicidade dirigida a crianças que as incentivem a comprar ou a consumir e, na Itália, é proibida a publicidade de qualquer produto ou serviço durante desenhos animados (FRAGOSO, 2009). Em países como a Dinamarca e Irlanda, são proibidas as publicidades durante os programas infantis. $\mathrm{Na}$ Holanda, não é permitido às televisões públicas interromper com publicidade os programas dirigidos às crianças menores de 12 anos (HENRIQUES, 2010).

No Brasil, a regulamentação governamental relativa à qualidade da alimentação infantil deveria estar pautada nos princípios constitucionais, no Código de Defesa do Consumidor e no Estatuto da Criança e do Adolescente. Porém, até o momento, é de responsabilidade do Conselho Nacional de Auto Regulamentação Publicitária - CONAR - realizar a supervisão de anúncios publicitários relacionados a esse segmento de consumidores.

Nesse sentido, em 25 de agosto de 2009, algumas das principais empresas multinacionais que atuam no setor de alimentos no Brasil assumiram compromisso espontâneo no sentido de acatar as 
normas instituídas pelo CONAR e aceitar limitações na publicidade de alimentos e bebidas para menores de 12 anos, incluindo propaganda nos meios de comunicação e promoções em escolas. O documento foi encaminhado ao Ministro da Saúde, que passou a assinar, a partir de 2007, acordos de cooperação técnica com a Associação Brasileira da Indústria de Alimentos - ABIA -, a Agência Nacional de Vigilância Sanitária ANVISA - e autoridades dos poderes Executivo, Legislativo e Judiciário, bem como governos estaduais e municipais.

Recentemente, a ANVISA publicou a resolução nº 24, de 15 de junho de 2010, com o propósito de assegurar o acesso a informações relativas à preservação da saúde a todos aqueles expostos à oferta, propaganda, publicidade, informação e promoção comercial dos alimentos com quantidades elevadas de açúcar, de gordura saturada, de gordura trans, de sódio e de bebidas com baixo teor nutricional. Além disso, essa resolução tem o objetivo de inibir práticas excessivas que levem o público, em especial o público infantil, a adotar padrões de consumo incompatíveis com a saúde e que violem seu direito à alimentação adequada.

Essa resolução dá especial importância à proteção dos consumidores de práticas que possam, por exemplo, omitir informações ou induzir ao consumo excessivo de alimentos de qualidade nutricional inadequada. Assim, proíbe símbolos, figuras ou desenhos que possam causar interpretação falsa, erro ou confusão quanto à origem, qualidade e composição dos alimentos. Também não permite atribuir características superiores às que o produto possui, bem como sugerir que o alimento é nutricionalmente completo ou que seu consumo é garantia de uma boa saúde. Além disso, ao divulgar ou promover alguns alimentos, devem ser veiculados alertas sobre os perigos do consumo excessivo de, por exemplo, alimentos com muito açúcar.

Em resposta a essa Resolução da ANVISA, 13 entidades e organizações - empresas industriais de alimentos, refrigerantes e bebidas e órgãos ligados à publicidade e propaganda - publicaram manifesto em diversos jornais de grande circulação do Brasil, em 07 de julho de 2010, alegando que a ANVISA exorbitava sua competência ao tentar impor regras à publicidade de alimentos e bebidas não alcoólicas (ZERO HORA, 07-07-2010). Em particular, é interessante notar que uma das associações que subscrevem esse documento, a ABIA, manifesta, em sua página na internet, que, entre os seus objetivos, estão o de "contribuir de forma a assegurar uma legislação adequada às constantes evoluções tecnológicas do alimento processado [...] e incentivar as melhores técnicas, o fortalecimento econômico-financeiro e o desenvolvimento da indústria da alimentação no Brasil, tendo sempre presente o interesse do consumidor” (ABIA, 2010).

No seguimento, atendendo à consulta do CONAR, a Advocacia-Geral da União - AGU recomendou, em 14 de julho de 2010, a suspensão da resolução no 24, de 15 de junho de 2010, pela ANVISA, alegando que é preciso avaliar se há necessidade de lei federal que regule a publicidade de alimentos e bebidas. Ao que a ANVISA divulgou, no dia seguinte, que a entidade faria uma reunião para estudar parecer, mas não suspenderia a resolução.

Dada essa polêmica, logo em seguida, entidades e organizações não governamentais ligadas à defesa do consumidor e à alimentação elaboraram uma carta em protesto à recomendação da AGU, carta essa assinada pelo Projeto Criança e Consumo, do Instituto ALANA, pelo Instituto Brasileiro de Defesa do Consumidor - IDEC -, pela Associação Brasileira de Nutrição - ASBRAN -, pelo Fórum Brasileiro de Soberania e Segurança Alimentar e Nutricional FBSSAN -, pelo Conselho Federal de Nutricionistas e pelo Observatório de Políticas de Segurança Alimentar e Nutrição da Universidade de Brasília - OPSAN -, refutando a argumentação da AGU e apontado que a ANVISA tem como missão "proteger e promover a saúde da população, garantindo a segurança sanitária de produtos e serviços e participando da construção de seu acesso" e que sua atribuição é criar regulamentos, controlar e fiscalizar a publicidade de produtos sob o regime da vigilância sanitária (EXAME ONLINE, 16-07-2010).

Em meio a toda essa mobilização, em setembro de 2010, a ABIA conseguiu a suspensão provisória da Resolução $n^{\circ}$ 24, por meio da $16^{a}$ Vara Federal de Brasília, que atendeu ao seu pedido de liminar, estabelecendo um impasse jurídico (ABIA, 2010). Assim, observa-se que a questão é controversa e ainda depende de discussões, inclusive no âmbito judicial.

Adequação das estratégias de posicionamento adotadas pelas indústrias alimentícias para a fidelização do consumidor infantil de alimentos

No mundo todo, existe consenso entre os especialistas de que, paralelo à crescente demanda por alimentos prontos e de vida de prateleira prolongada (GALIZZI \& VENTURINI, 1996; HUGUES, 1996; TRAIL, 1997)e à ascensão do consumo de refeições rápidas e snacks - muitas vezes fora do lar (HUGUES, 1996; STEENKAMP, 1997; MEULENBERG \& VIAENE, 1998), crescea exigência dos consumidores por alimentos de melhor qualidade (STEENKAMP, 1997;TRAIL, 1997; WIERENGA, 1997), 
em particular, a demanda por produtos “mais saudáveis” (com baixo teor de gordura, colesterol, sódio ou calorias, isento de defensivos químicos, com garantia de food safety) (CHRISTENSEN et al., 1996; HUGUES, 1996; STEENKAMP, 1997; TRAIL, 1997; MEULENBERG \& VIAENE, 1998; LAPPALAINEN et al., 1998,BROWNELL\&HORGEN,2004; GEREFFIetal., 2009).

Nesse sentido, ações incentivando o consumo de alimentos mais saudáveis são empreendidas em diversos países desenvolvidos. Citam-se, como exemplos dessas ações, os programas “6 om Dagen” (Dinamarca) e "5 a day” ( EUA, Reino Unido, Alemanha, Austrália e Nova Zelândia). O primeiro incentiva o consumo de frutas e legumes de, pelo menos, 600 gramas por dia para adultos e 300-500 gramas para crianças de 4 a 10 anos. O segundo preceitua o consumo de, no mínimo, cinco porções de frutas e verduras diariamente, tendo como atividade principal o desenvolvimento de recursos educacionais para educadores em centros infantis, escolas primárias e intermediárias com vistas a promover a alimentação saudável (BERESFOR et al., 2001).

No Brasil, estima-se que o consumo de alimentos “saudáveis” evoluiu de um patamar de R \$15,9 bilhões, em 2004, para R\$ 28,9 bilhões, em 2009, apresentando um crescimento de $82 \%$ nos últimos cinco anos. O Serviço Brasileiro de Apoio às Micro e Pequenas Empresas SEBRAE - apresenta projeções de que, até 2014, o consumo desses alimentos cresça mais 39\% e atinja em torno de R\$39,2 bilhões (SEBRAE, 2010).

A tendência do consumidor à opção por alimentos mais saudáveis também foi identificada em pesquisa encomendada pela Associação Brasileira de Embalagens ao Instituto de pesquisa LatinPanel (ABRE, 2009). O estudo aponta que $22 \%$ das donas de casa brasileiras declararam que suas decisões de compras levam em consideração a saudabilidade dos alimentos; 72\% sempre consultam o prazo de validade; $82 \%$ leem rótulos dos produtos (39\% sempre); 59\% buscam produtos com baixo teor de gordura e colesterol e $52 \%$ verificam as calorias dos produtos. Esses dados corroboram a conjectura de que o mercado de produtos saudáveis é um nicho de mercado em expansão no Brasil.

De fato, em estudo publicado recentemente, existe uma tendência de mudança no padrão alimentar do brasileiro, que tem buscado alimentos e bebidas mais saudáveis (EUROMONITOR, 2010). De acordo com a pesquisa, as vendas no varejo de alimentos funcionais, diet, light, orgânicos e produtos específicos para quem tem intolerância a certos tipos de alimentos passaram de US\$ 8,5 bilhões, em 2004, para US\$ 15,5 bilhões, em 2009. Os principais fatores que contribuíram para esse crescimento do setor foram o envelhecimento da população, o aumento do poder aquisitivo do brasileiro e a proliferação de doenças ligadas aos maus hábitos alimentares.

Em particular, pesquisa da INTERSCIENCE (2003) relacionada ao comportamento do consumidor de produtos alimentícios e à emergência de novas oportunidades indica a importância de um novo posicionamento do setor de alimentos que propicie: (a) a saudabilidade dos alimentos fabricados; (b) o enriquecimento desses com vitaminas; (c) o não uso de conservantes; e (d) a confiabilidade da marca. Evidenciam-se também algumas alternativas para atrair o consumidor infantil, ao mesmo tempo em que as expectativas dos pais são atendidas, como: o monitoramento da qualidade dos produtos oferecidos, o lançamento de novos produtos, o cuidado na manutenção e na qualidade das embalagens; e uma propaganda lúdica e verdadeira.

Uma pesquisa de ALFASSI et al. (2005) constatou que o público-alvo da inclusão de alimentos saudáveis no cardápio, bem como da campanha de marketing, são pessoas mais jovens, de alto poder aquisitivo, que possuem maior preocupação com alimentação e saúde.

Focando a fidelização desse público, atualmente, algumas empresas de alimentos estão incrementando a oferta de produtos mais saudáveis (com teor reduzido de calorias, gordura e açúcar e com a adição de fibras e vitaminas) para o público infantil.

Cita-se a Nestlé (empresa com portfólio variado de produtos para o consumidor infantil), que apresenta, em seu website, informações relativas a: (a) tipo de alimentação saudável de acordo com a idade; (b) pirâmide alimentar; (c) vitaminas e minerais; (d) prática de exercícios físicos. A empresa também passou a produzir bebidas, iogurtes, cookies e barras de cereais à base de soja, lançando ainda sopas com reduzido teor de gordura e sódio. De acordo com HONDA et al. (2009), a Nestlé tem como estratégia continuar investindo em produtos com alto valor agregado, voltados à saúde e ao bem-estar para o púbico adulto e infantil. Considerando essa estratégia, em janeiro de 2010, a Nestlé inaugurou o Centro Global de Pesquisa e Desenvolvimento em Santiago, no Chile, para conduzir pesquisas voltadas ao desenvolvimento de tecnologias para a produção de biscoitos e produtos a base de cereais, com diminuição de açúcar e gordura, porém com manutenção do sabor (NESTLÉ, 2010). Na Nestlé, houve um crescimento de $23 \%$ no faturamento dos alimentos com apelo de produtos saudáveis, contra um incremento de somente 6\% nas vendas globais da empresa em 2008 (MATTOS, 2009).

Do mesmo modo, a empresa Unilever aproveitou essa tendência e investiu, por exemplo, em 
novos produtos para a marca Becel, pela sua associação ao conceito de saúde, por ser esta considerada uma alternativa à manteiga e margarinas duras, ricas em gordura poliinsaturada. O slogan da empresa "sentir-se bem, ficar bonito e aproveitar mais a vida" denota um posicionamento da empresa com vistas à saúde e ao bem-estar dos consumidores. Em 2008, essa empresa lançou maionese nas versões light (com 25\% menos de sal e com Omega-3) e linhas de temperos em cubo, sopas desidratadas e molhos de tomate com $20 \%$ menos de sal e com menor teor de gorduras (UNILEVER, 2010).

Da mesma forma, a companhia PepsiCo também vislumbra a produção de alimentos mais saudáveis nos próximos dez anos, com a diminuição dos níveis de sal, açúcar e gordura saturada em 25\% em seus produtos. A companhia divulgou que tem também a intenção de ampliar a presença de grãos integrais, frutas e vegetais em seus produtos (CARDOSO, 2010).

Nessa linha de convergência, a empresa Elegê passou a produzir linhas de leites especiais enriquecidos com ferro, vitamina $\mathrm{C}$ e vitamina $\mathrm{A}$, apresentando, por exemplo, linhas de: a) leite UHT semidesnatado, enriquecido com cálcio e vitamina D; (b) leite UHT com baixo teor de lactose; (c) leite UHT desnatado com adição de fibra alimentar solúvel; e (d) leite UHT integral, rico em ferro (ELEGÊ, 2010).

Com vistas à fidelização do público infantil e com base nos dados de pesquisa realizada pela Danone Research, em conjunto com diversas instituições de ensino e pesquisa, sob a coordenação do pediatra e nutrólogo Mauro Fisberg, a empresa Danone aprimorou a fórmula do seu petit suisse, aumentando a quantidade de cálcio e acrescentando vitamina $E$ a esse produto. A pesquisa citada analisou os hábitos alimentares de 3.111 crianças brasileiras na faixa etária de dois a seis anos, evidenciando a falta de cálcio na alimentação das crianças com idade de 4 a 6 anos, sendo que $57 \%$ delas não ingerem as quantidades recomendadas do mineral (FISBERG, 2009).

Na direção dessa demanda, a Kellogg’s Brasil, uma das marcas líderes no mercado de cereais matinais voltados ao consumo de adultos, jovens e crianças, lançou, em 2010, uma linha de biscoitos ricos em fibras, vitaminas e minerais. A empresa também apresenta, em seu website, um guia nutricional interativo, evidenciando os benefícios do entendimento do valor nutricional dos alimentos (KELLOGG'S BRASIL, 2010).

As empresas fornecedoras de matéria prima para a indústria igualmente já observam essa tendência. A empresa Bunge, uma das principais empresas desse segmento no Brasil, visando a fornecer ingredientes para a indústria de alimentos que busca atender à demanda crescente de consumidores que procuram produtos mais saudáveis e de uma perspectiva de mudanças na legislação regulatória, lançou, em 2009, uma linha de produtos especiais com a identificação "low trans, low sat", que contém baixo teor de gorduras trans e de gordura saturada na mesma formulação (BUNGE, 2009).

Pode-se observar, ainda, que algumas redes de fast food, como o McDonald's, têm oferecido também produtos mais saudáveis, com inclusão, em seu cardápio, de saladas, maçãs, etc. (ALFASSI et al., 2005). Na mesma linha, a Burger King no Brasil lançou, em 2010, novos produtos em refeições para crianças, incluindo sucos de maçã, purê de maçã e chicken tenders com baixo teor de sódio.

De fato, existe uma demanda crescente por produtos mais saudáveis para o público infantil no Brasil e no mundo, gerando um mercado atraente. Assim, o pioneirismo pode ser uma oportunidade para a indústria alimentícia conquistar esse mercado emergente, mediante a inovação na oferta de produtos e a comunicação de informações de forma ética e transparente.

O diálogo entre os organismos da sociedade e regulamentadores com indústrias de alimentos processados, meios de comunicação e marketing deve ser aprofundado com vistas a eliminar a promoção de produtos alimentícios que contribuem para dietas que levem a problemas de saúde na infância e na adolescência. Já são observadas, mesmo que em ritmo lento, a adoção de estratégias de algumas empresas no sentido de começaram a alterar os componentes dos seus produtos a fim de torná-los menos prejudiciais à saúde. Essa iniciativa é bem acolhida e deve prosseguir sistematicamente, em escala e ritmo mais intensos.

\section{CONCLUSÃO}

Esta pesquisa evidenciou que a adoção de padrões de alimentação inadequados tem gerado a emergência de novos problemas de saúde na população infantil brasileira. Esse quadro é agravado por um contexto institucional marcado pelo conflito de parte do setor processador de alimentos e órgãos públicos de regulação, em particular no que diz respeito à competência de regular a publicidade de alimentos para esse segmento de consumidores.

Contudo, o estabelecimento de normativas por órgãos públicos, isentos de uma regulamentação rígida e específica relativa às informações veiculadas na propaganda e publicidade voltadas ao público infantil, beneficia não apenas os consumidores, mas também pode privilegiar as empresas realmente 
preocupadas em garantir a boa qualidade de seus produtos e informar corretamente o consumidor.

Aberta essa discussão, este trabalho apontou fatores relacionados às perspectivas atuais de mercado com vistas à fidelização dos consumidores infanto-juvenis de alimentos, assinalando algumas estratégias emergentes na indústria alimentícia, adequadas a esse novo contexto. Constata-se que algumas empresas do segmento alimentício, reconhecendo esse processo como uma tendência inexorável de consumo, iniciam o alinhamento da oferta a essa nova tendência do mercado brasileiro, que começa a demandar alimentos processados mais saudáveis. Embora timidamente, a indústria brasileira de alimentos já manifesta um movimento no sentido de industrializar, comercializar e desenvolver estratégias apropriadas de divulgação de produtos alimentícios com maior saudabilidade, porém, há um longo caminho a ser percorrido para a ampliação e adequação desses produtos a esse novo posicionamento.

\section{REFERÊNCIAS}

ABIA. Associação Brasileira das Indústrias da Alimentação. Home Page. Disponível em: <http://www.abia.org.br/ quemsomos.asp>. Acesso em: 16 jul. 2010.

ABRE. Associação Brasileira de Embalagem. Para onde caminha o consumidor? Pesquisa LatinPanel, 29 jul. 2009. Disponível em: <http://www.abre.org.br/abre_imprensa/ 0708.html>. Acesso em: 3 set. 2010.

ALFASSI, E. et al. McDonald's com cardápio saudável? In: SEMEAD, 8., Seminário em Administração FEA-USP, 2005, São Paulo. Disponível em: <http://www.ead.fea.usp.br/Semead/8semead/ resultado/trabalhosPDF/370.pdf>. Acesso em: 29 jul. 2010.

ANVISA. Agência Nacional de Vigilância Sanitária. Resolução n. 24, de 15 de junho de 2010. Disponível em: <http://portal.anvisa.gov.br/ wps/wcm/connect/483f7600431dbf36bfc6bf9c579bb600/ RDC24_10_Publicidade+de+alimentos.pdf?MOD=AJPERES>. Acesso em: 10 jul. 2010.

BERESFOR, S.A.A. et al. Seattle 5 a day worksite program to increase fruit and vegetable consumption. Preventive Medicine, v.32, n.3, p.230-238, 2001.

BROWNELL, K.; HORGEN, K.B. Food fight: the inside story of the food industry, America's obesity crisis, and what we can do about it. Nova York: McGraw-Hill, 2004. 356p.

BUNGE. Notícias. Bunge traz produtos com novo conceito de saudabilidade para a Health Ingredients. Junho de 2009. Disponível em: <http://www.bunge.com.br/empresa/ noticias.asp?id=322>. Acesso em: 2 set. 2010.

CAIRNS, G. et al. The extent, nature and effects of food promotion to children: a review of the evidence to december 2008. Prepared for the world health organization. United Kingdom: Institute for Social Marketing, University of Stirling
\& The Open University, December 2009. Disponível em: $<$ https://www.who.int/dietphysicalactivity/Evidence_Update_2009.pdf $>$. Acesso em: 25 jun. 2010.

CARDOSO, J. PepsiCo cortará sal, açúcar e gordura saturada de seus produtos. Revista Valor On-line, de 23 de março de 2010. p.1 Disponível em: <http:/www.valoronline.com.br/online/bebidas/ 46/292933/pepsico-vai-cortar-sal-acucar-e-gordura-saturada-deseus-produtos?quicktabs_3=1>. Acesso em: 4 set. 2010.

CHRISTENSEN, J.L. et al. Innovation in the european food products and beverage industry. Industry studies of innovation using C.I.S. data. Bruxelles (BEL): European Commission EIMS Project 94/111, 1996. (EIMS Publication n.35).

ELEGÊ. Site institucional: produtos da linha leite especial Elegê. Disponível em: <http://www.elege.com.br/ lista_produtos.cfm?marca=3\&linha=25>. Acesso em: 1 set. 2010.

EXAME ON-LINE. Publicidade de alimentos: ONGs reagem à recomendação da AGU e defendem regulamentação - Carta defende a Resolução n.24, da Anvisa, que prevê regulamentação da publicidade de alimentos. Revista Exame Popmark On-line, 16 jul. 2010. p.1 Disponível em: <http://portalexame.abril.com.br/ marketing/noticias/ongs-reagem-recomendacao-agu-defendemregulamentacao-579111.html>. Acesso em: 18 jul. 2010.

EUROMONITOR. Euromonitor International. Consumer Latin America 2010. Disponível em: <http://www.euromonitor.com/ Consumer_Latin_America>. Acesso em: 14 jun. 2010.

FISBERG, M. (Coord.). Estudo nutri-brasil infância: estudo multicêntrico do consumo alimentar de pré-escolares. Jornada de Atualização Pediátrica SPSP, Campinas, SP, 29 de agosto de 2009. Disponível em: <http://www.ilsi.org.br/fortificadosla/ apresentacoes/Mauro_Fisberg.pdf>. Acesso em: 2 set. 2010.

FRAGOSO, P.A.D. A experiência da regulamentação das campanhas publicitárias de cigarro como subsídio para a comunicação de alimentos direcionados ao público infantil no Brasil. In: VIVARTA, V. (Coord.). Infância e consumo: estudos no campo da comunicação. Brasília, DF: ANDI; Instituto Alana, 2009. p.47-58.

GALIZZI, G; VENTURINI, L. Product innovation in the food industry: nature, characteristics and determinants. In: (Eds.). Economics of innovation: the case of food industry. Heidelberg (Alemanha): Physica Verlag, 1996. p.133-145.

GEREFFI, G. et al. US-based food and agricultural value chains and their relevance to healthy diets. Special Issue: food systems and public health: linkages to achieve healthier diets and healthier communities. Journal of Hunger \& Environmental Nutrition, v.4, n.3, p.357-374, 2009.

HENRIQUES, I.V.M. Publicidade abusiva: comerciais televisivos. Carta enviada ao Ministério Público do Estado de São Paulo - Promotoria de Justiça do Consumidor, 2008. Disponível em: <http://www.alana.org.br/banco_arquivos/ arquivos/docs/acoes/dolly/dolly_representa\%C3\%A7\% C3\%A3o_27-9-08.pdf>. Acesso em: 18 jun. 2010.

Instituto Alana. Projeto criança e consumo. Disponível em: <http://www.alana.org.br/CriancaConsumo/>. Acesso em: 16 maio, 2010.

HONDA, A. et al. Consumidores em busca da saúde. 01/12 2009. Disponível em: <http://healthyworldic.wordpress.com/>. Acesso em: 2 set. 2010 
HUGUES, D. Building partnerships and alliances in the european food industry. In: GALIZZI, G.; VENTURINI, L. (Eds.). Economics of innovation: the case of food industry. Heidelberg (Alemanha): Physica Verlag, 1996. p.100-117.

IBGE. Instituto Brasileiro Brasileiro de Geografia e Estatística. Pesquisa de Orçamentos Familiares 2008-2009. Disponível em: <http://www.ibge.gov.br/home/presidencia/ noticias/noticia_visualiza.php?id_noticia=1699\&id_pagina=1>. Acesso em: 14 ago. 2011.

IDEC. Instituto Brasileiro de Defesa do Consumidor - 2009. Pesquisa do Instituto Brasileiro de Defesa do Consumidor (Idec); analisa 30 alimentos industrializados destinados a crianças. Disponível em: <http://www.idec.org.br/>. Acesso em: 20 jun. 2010.

INTERSCIENCE, Informação e Tecnologia Aplicada. 2003. Como atrair o consumidor infantil, atender expectativas dos pais e ainda, ampliar as vendas... Disponível em: <http:/ /www.alana.org.br/banco_arquivos/arquivos/docs/biblioteca/ pesquisas/interscience_influencia_crianca_compra.pdf $>$. Acesso em: 15 maio, 2010.

KELLOGG'S BRASIL. Site Institucional. Disponível em: <http://www.kellogg.com.br/>. Acesso em: 6 set. 2010.

LAPPALAINEN, R. et al. A Pan EU survey of consumer attitudes to food, nutrition and health: an overview. Food Quality and Preference, v.9, p.467-478, 1998.

MATTOS, A. O bem-estar da Nestlé: empresa reconhecida pelos produtos calóricos triplica a venda de itens saudáveis que garantem margem de lucro mais gorda. Revista Isto é dinheiro. Ed.634. 02 dez. 2009. p.1. Disponível em: <http:/ /www.istoedinheiro.com.br/ noticias/428_O+BEMESTAR+ DA+NESTLE $>$. Acesso em: 24 jun. 2010.

MEULENBERG, M.T.G. et al. (Eds.). Innovation in the production systems - Product quality and consumer acceptance. Wageningen: Wageningen Pers, 1998. 182p.

NESTLÉ. Site Institucional. Disponível em: <http://www.nestle.com.br/>. Acesso em: 4 set. 2010.

PESSOA, A.C. O perfil da mulher executiva. Revista Exame, ed.868, p.14, 2006.

SAMPAIO, I.S.V. Publicidade e infância: uma relação perigosa. In: VIVARTA, V. (Coord.). Infância e consumo: estudos no campo da comunicação. Brasília, DF: ANDI; Instituto Alana, 2009. p.09-21.

SEBRAE. Agência SEBRAE de Notícias. 21.05.2010. Consumo de alimentos saudáveis no Brasil cresce $82 \%$ : feiras do setor realizadas esta semana em São Paulo mostram fôlego e atraem grandes redes de supermercados. Disponível em: <http:/www.agenciasebrae.com.br/ noticia.kmf?canal $=199 \&$ cod $=10042595 \&$ indice $=0 \mathrm{www}>$. Acesso em: 23 jun. 2010.

SOCIEDADE BRASILEIRA DE PEDIATRIA. Obesidade na infância e na adolescência. 2008. Disponível em: <http:// www.sbp.com.br/PDFs/Man\%20Nutrologia_Obsidade.pdf $>$. Acesso em: 17 jun. 2010.

SCHOR, J.B. Nascidos para comprar: uma leitura essencial para orientarmos nossas crianças na era do conhecimento. Tradução Eloisa Helna de Souza Cabral. São Paulo: Editora Gente, 2009. 344p.

STEENKAMP, J-B. E.M. Dynamics in consumer behavior with respect to agricultural and food products. In: WIERENGA, B. et al. (Eds.). Agricultural marketing and consumer behavior in a changing world. Boston: Kluwer Academic Publishers, 1997. p.143-188.

TRAIL, B. Structural changes in the European food industry: consequences for innovation. In: TRAIL, B.; GRUNERT, K.G. Product and process innovation in the food industry. Suffolk: Chapman \& Hall, 1997. p.35-57.

UNILEVER. Programa minha escolha: para facilitar escolhas saudáveis, a Unilever investe na melhoria do perfil nutricional de seus produtos e na comunicação de seus valores. Disponível em: <http://www.unilever.com.br/brands/nutricao/ programa_minha_escolha/>. Acesso em: 15 jul. 2010.

UNIFESP. Jornada de Propaganda de Alimentos e Obesidade na Infância e Adolescência. São Paulo: Escola Paulista de Medicina da UNIFESP, 2005. 100p.

VILLELA, A.L. Instituto Alana. Projeto criança e consumo: origem e missão. Disponível em: <http://www.alana.org.br/ CriancaConsumo/Projeto.aspx>. Acesso em: 18 jun. 2010.

ZERO HORA. Manifesto contrário à Resolução n.24/2010, da ANVISA. Jornal Zero Hora, Porto Alegre, 07 jul. 2010. Caderno de economia, p.23.

WHO. Marketing of food and non-alcoholic beverages to children: report of a WHO forum and technical meeting. Oslo, Norway, 2-5 May 2006. Disponível em: <http:// www.who.int/dietphysicalactivity/publications/ Oslo\%20meeting\%20layout\%2027\%20NOVEMBER.pdf>. Acesso em: 19 jun. 2010.

World Health Organization. may 2010. Updated WHO recommendations on marketing of foods and nonalcoholic beverages to children. Disponível em: <http:// www.who.int/en/>. Acesso em: 22 jun. 2010.

WIERENGA, B. Competing for the future in the agricultural and food channel. In: _____. et al. (Eds.). Agricultural marketing and consumer behavior in a changing world. Boston: Kluwer Academic, 1997. 314p. 